\title{
Editorial
}

\section{Cooperative Longevity: Why Are So Many Cooperatives So Successful?}

\author{
Constantine Iliopoulos $1, *(\mathbb{D})$ and Vladislav Valentinov ${ }^{2}$ \\ 1 Agricultural Economics Research Institute (AGRERI), Nik. Chlorou 1, 11528 Athens, Greece \\ 2 Leibniz Institute of Agricultural Development in Transition Economies (IAMO), and Interdisciplinary \\ Research Unit on Cooperative Studies, Martin Luther University, Große Steinstrasse 73, 06099 Halle, \\ Germany; Valentinov@iamo.de \\ * Correspondence: iliopoulosC@agreri.gr; Tel.: +30-210-275-5086
}

Received: 26 September 2018; Accepted: 27 September 2018; Published: 27 September 2018

\begin{abstract}
Despite popular misconceptions, cooperatives present a very successful organizational form worldwide. A recent study found that in the U.S., for example, 134 agricultural cooperatives celebrated their 100th anniversary in 2014. This observation on cooperative longevity is not matched by a corresponding research effort on what makes cooperatives so successful. Most of the extant research seems to focus on intra-cooperative problems that posit significant challenges to cooperatives. This special issue of Sustainability bridges the considerable gap between scholarly work and reality. By focusing on what makes cooperatives so successful for such a long period of time, this issue sheds light on key aspects of cooperative longevity. Bridging social capital, fundamental solutions to excessive heterogeneity-induced high ownership costs, tinkering, cooperative genius, and superior capacity to adapt to shocks and changes are among the factors identified to explain extended cooperative longevity. The insights thereby gained are useful to students of cooperatives, practitioners, and policy makers.
\end{abstract}

Keywords: cooperatives; longevity; organizational costs; systems thinking

\section{Introduction}

The motivation for putting together this special issue is the observation that despite popular misconceptions, cooperatives present a very successful organizational form worldwide (e.g., [1,2]). A recent study found that in 2014, 134 U.S. agricultural cooperatives were celebrating 100 or more years since their formation [1]. The majority of these organizations were started between 1887 and 1914. Similar results are reported on numerous European countries [2]. While this special issue focuses almost exclusively on agricultural cooperatives, research seems to support the same conclusions with respect to non-agricultural cooperatives, too (e.g., [3]).

The aforementioned observation on cooperative longevity is not matched by corresponding research efforts on what makes cooperatives so successful. Most of the extant research seems to focus on intra-cooperative problems that posit significant challenges to cooperatives. This special issue of Sustainability aims at bridging the considerable gap between scholarly work and reality. By focusing on what makes cooperatives so successful for such a long period of time, this issue sheds light on key aspects of cooperative longevity. The insights thereby gained are useful to students of cooperatives, practitioners, and policy makers.

The current editorial is structured in four sections. Following the introduction, the next section outlines the themes and insights that emerge from the contributions of the special issue. Section 3 provides a methodological reflection on the factors constraining cooperative longevity. The last section 
highlights research issues, themes and questions that have not been addressed yet but whose inquiry will provide a more holistic understanding of cooperative firms.

\section{Emerging Themes and Insights from the Special Issue}

The papers in this special issue address cooperative longevity from a variety of angles, perspectives, and theoretical lens. They refer to completely different institutional, legal, and cultural contexts, which makes their conclusions rich and interesting for both scholars and practitioners. This is more so because some of these papers focus primarily or exclusively on theoretical and conceptual questions while others provide empirical answers to research questions.

Bijman studies the evolution of Dutch dairy cooperatives in an attempt to shed light on the issue of cooperative survival and success [4]. The initially increasing and then declining number of dairy cooperatives in the Netherlands is observed in parallel with a constantly increasing market share. Following the formation of the first Dutch dairy cooperative in 1886, the number of these organizations reached a peak in 1916 when 750 cooperatives were active. Subsequently this number started declining to five dairy cooperatives in 2015. At the same time, the combined market share of these cooperatives kept increasing to reach $86 \%$ in 2015. Bijman argues that it is a combination of theoretical explanations that explain these trends.

Realization of economies of scale unattainable at the individual farm level provides a partial explanation of both the farmers' decision to form collective entrepreneurship organization but, also, the decision of dairy cooperatives to merge; hence the observed decline in the number of dairy cooperatives. Another explanation is provided by farmers' need to address various forms of market failures (e.g., spatial monopolies) by increasing their bargaining power vis-à-vis sundry milk supply chain partners. The need to reduce transaction costs, particularly during the first wave of cooperative formations in the late 1800's and early 1900's is yet another factor that explains dairy cooperative formation. Bijman suggests that in the future transaction costs minimization might still be a significant motivation for dairy farmers to remain members of cooperatives due to significant quasirents in the form of physical asset specificity and dedicated assets. Finally, the author proposes the institutional environment and support as crucial parameters that have motivated both the emergence and survival of dairy cooperatives. These have taken, among others, the form of supportive cooperative legislation, quality regulations, milk market ordering, state support for dairy farming, etc.

Chlebika and Pietrzak study the potential relationship between the survival of Polish producer organizations and farmers' social capital [5]. They focus on two research questions: (1) does the size of membership matter for the survival of producer organizations? and (2) is the stock and structure of social capital (bonding vs bridging social capital) the key factors that differentiate the size of established producer organizations? They adopt a systems thinking approach to dynamic complexity and use primary and secondary data on Polish agricultural producer organizations to address these questions. According to their results, the size of membership is not a decisive factor with respect to the longevity of these organizations. Smaller producer organizations thrive based on kinship bonds among their members while bigger organizations are more embedded in acquaintance relations. The authors also find that the stock of bridging capital plays a far more important role in larger organizations than in smaller ones.

Cook introduces a cooperative lifecycle framework (LCF) based on his several decades of theoretical and empirical research, as well as numerous interviews, focus groups, workshop discussions, etc., with more than 5000 cooperative leaders [6]. Cook's cooperative life cycle unravels in five phases: (1) economic justification; (2) organizational design; (3) growth-glory-heterogeneity; (4) recognition and introspection; and (5) choice. Unlike most, if not all, life cycle theories of investor-oriented firms (IOFs), Cook's conceptual framework suggests that agricultural cooperatives can live through succeeding life cycles, as long as they manage to minimize ownership costs and keep them well below perceived market contracting costs. 
High ownership costs in cooperatives result from a significant divergence in member preferences, usually first observed during phase three of the life cycle. While heterogeneity of member attributes and preferences can potentially have a significantly positive impact on several aspects of cooperatives' operations, if left unchecked, and due to diachronic increases, can result in excessive ownership costs. The latter manifest themselves as frictions and factions that may cause degeneration. Addressing these frictions efficiently and effectively is a decisive factor in avoiding degeneration.

This is done primarily in phase three by cooperatives that have a high level of what he calls "cooperative genius" and are involved in continuous "tinkering". According to Cook, cooperative genius is "... a process executed by employees and members who understand the value to the member and the cooperative of minimizing collective decision-making costs." Tinkering modifies practices and adjusts member-patron accepted operational mechanisms in aligning preferences and incentives of the membership or a membership subset. Tinkering does not result in significant changes in ownership rights. The process of cooperative genius involves the implementation of a large number of successful tinkering-style modifications or, as referred to by Cook and Iliopoulos [7], generic solutions to frictions arising from high ownership costs. These solutions fall into one of four categories: (a) user alignment; (b) member retention; (c) supply/demand balancing; and (d) transparency [7].

Yet, cooperatives may reach a point (at the end of phase three) where tinkering doesn not suffice to tackle excessive frictions and their consequences. Subsequently, organizations that recognize the underlying, systemic, problems go through a period of introspection (phase four) and, finally, realize that they need to address the root causes of high ownership costs, the so called vaguely defined property rights (VDPRs), which are manifested as free rider, horizon, portfolio, influence costs, and control problems. They do so by choosing from a menu of four options: (1) reinvent; (2) status quo; (3) spawn; and (4) exit. Adopting the status quo option implies that membership waits for an outside savior, who usually never comes. Thus the status quo solution usually results in the fourth option, too. This is exit, in which the cooperative no longer bases ownership rights on patronage. Spawning refers to a process where a new entity is formed by part of employees and membership. Finally, cooperatives that reinvent themselves successfully modify one or more of the following: cooperative purpose, organizational culture, and/or member-patron ownership rights. Cooperatives that succeed in making these changes can go through succeeding life cycles and thus avoid degeneration.

Thus Cook's explanation of cooperative longevity is straightforward: cooperative health is maximized in the long run, that is, cooperatives avoid degeneration by designing efficient and effective solutions to excessively high ownership costs.

Elliott et al. study the effects of cooperative membership heterogeneity on the sustainability of U.S. farmer cooperatives [8]. They use predictive analytics to forecast cooperative sustainability at an aggregate level and include multiple dimensions of membership heterogeneity. Their empirical research is based on the analysis of data from the United States Department of Agriculture (USDA)-Economic Research Service (ERS), more particularly data from the Agricultural Resource Management Survey (ARMS) and USDA-Rural Development cooperative financial data at the state level. Elliott et al. find that membership heterogeneity affects the number of cooperatives headquartered in a state and, more generally, cooperative sustainability. The authors find little evidence that heterogeneity explains cooperative gross business volume at the state level compared to the amount of value-added by the farm. Instead, they report that cooperative member diversity in farm size better forecasts, at least part of, sustainability. On the contrary, membership heterogeneity proves to be more relevant in understanding the rate of consolidation and acquisition of U.S. cooperatives.

Elliott et al. predict that, at least in the short run, cooperative sustainability might be positively influenced by greater member aging, more member asset value, greater value added at the farm level, and greater diversity of farm size in some regions. However, their analysis does not include data on member preferences that might add a completely different perspective on member heterogeneity; some of the classics on this topic suggest that member preference heterogeneity can be a far more important ingredient of member heterogeneity (e.g., [9]). At the same time, the authors highlight the fact that 
cooperative sustainability is a multidimensional concept and thus extremely difficult to measure with accuracy. They also hint at the need to analyze primary, more micro-level data in order to delve into the most important dimensions of both sustainability and member preference heterogeneity.

Giagnocavo et al. focus on cooperatives active in the fruit and vegetable industry of Almeria, Spain [10]. They review a number of studies on these organizations and conclude that the longevity and survival of these organizations are linked to their ability to constantly adapt to industry crises and challenges. Almeria cooperatives achieve this by adapting to and addressing the distinct economic, social, and environmental demands of their member-owners. The authors highlight the need to include in any analysis of cooperative longevity indicators in addition to the standard profit or financial ones used in studying IOFs. Examples include services provided to members, such as market access and boosted bargaining power vis-à-vis powerful food supply chain partners, significant contributions to knowledge systems and local employment (with emphasis placed on women and foreign workers), and promotion of equitable income.

At the same time, cooperatives in Almeria make substantial contributions to sustainable water, soil and waste management, reduction of pesticide use, promotion of renewable energy productions and consumption, as well as to maintenance of the small family farm system of agricultural production.

Grashuis focuses on agricultural cooperatives' strategic adaptation to external developments over the years [11]. In his exploratory meta-study he reviews a number of studies and uses secondary data to addresses the research question of "how have farmer cooperatives responded to industry consolidation, consumer segmentation, price volatility, and policy change to spur survival and longevity?" The scope of his study includes cooperatives from North America, Europe, and Australia. Grashuis concludes that agricultural cooperatives tend to respond to significant changes in their external environment by means of organic growth. Among the most common forms of this growth included are geographic expansion, portfolio diversification, and vertical integration. The downside of such adaptation strategies, though, is that cooperatives may become more susceptible to internal inefficiencies, which might force them to exit [6]. For example, the free rider, horizon, and portfolio constraints to cooperative equity attraction may become even more binding when a cooperative adopts an organic growth strategy. Examples of agricultural cooperatives converted to IOFs due to the pursuit by cooperatives of investor-oriented objectives that, finally, resulted in extremely high ownership costs include: Calavo, Diamond Walnut Growers, Dakota Growers Pasta Company, etc. Yet, the author mentions a number of old, large cooperatives from various countries, whose survival provides partial evidence of their ability to adapt to dynamic as opposed to static situations.

Iliopoulos and Valentinov study under what conditions member preference heterogeneity becomes a threat to cooperative longevity and what types of solutions seem to address this organizational risk effectively [12]. The authors argue that most currently proposed solutions to the frictions caused by excessive member preference heterogeneity are symptomatic rather than fundamental. Consequently, the underlying causes remain unaddressed. Searching for fundamental solutions, Iliopoulos and Valentinov draw on the Luhmannian system-environment paradigm. Bringing this paradigm to bear on the cooperative scholarship, they view cooperatives as operationally closed systems maintaining a precarious relationship to their outer environment, which includes cooperative members. In view of their operational closure, cooperatives tend to overstrain the carrying capacity of their environment by being active in the areas marked by a limited extent of the true commonness of member interests. This overstraining results in a host of problems associated with member heterogeneity. The fundamental solutions following from the system-environment paradigm require the adjustment of cooperative boundaries and goals in light of the evolving range of the true common interests of members.

Tortia provides a new institutional perspective on the observed extended longevity of cooperatives relative to other entrepreneurial forms [13]. He views non-divided asset ownership in cooperatives as being similar or identical to the management of common-pool resources. Subsequently, he focuses on common or non-divided asset ownership and, particularly on the self-financed accumulation and use 
of capital. The author attempts to explain the pattern of emergence and spread (both spontaneous and legally mandated) of non-divided capital reserves, interpreted as deductible and non-excludable assets, and to identify the main economic forces defining their optimal level. His theoretical analysis suggests that the aforementioned patterns are explained by the relatively higher transaction and operating costs associated with individualized reserves of capital. Tortia suggests that the main implication of his analysis is that common resources, when tragedy of the commons-like social dilemmas are overcome, can represent a fundamental and empowering tool allowing members to achieve higher welfare and empowerment thus explaining the remarkable longevity of cooperatives. Hence, the author concludes that, in the case of non-divided ownership of key cooperative assets, free rider and other collective action constraints reported in the empirical literature may not be as binding as expected. Tortia's observations about the emerging patterns of asset ownership are drawn primarily, if not exclusively, from non-agricultural cooperatives. This might partially explain the divergence between some of the author's conclusions and the current state of the knowledge on high ownership and organizational costs in agricultural cooperatives and the resulting organizational inefficiencies.

The following table summarizes the factors proposed by each of the papers in this special issue as key in explaining extended cooperative longevity.

Table 1 proposes several factors, more or less expected to influence cooperative longevity. Yet, the same table suggests that there is more to the picture than usually meets the eye. Concepts such as tinkering, cooperative genius, bridging social capital, and fundamental solutions to member preference heterogeneity imply that focusing on single-dimension factors (economic, social, cultural, interpersonal, etc.) might miss $90 \%$ of the cooperative iceberg, which lied beneath the surface. A more holistic, systemic view of cooperative longevity is guaranteed. The next section reflects on methodologies that may be used to study the factors limiting cooperative longevity.

Table 1. Factors explaining extended cooperative longevity identified in this Special Issue.

\begin{tabular}{|c|c|}
\hline Paper in This Special Issue ... & Factors Explaining Extended Cooperative Longevity ... \\
\hline Bijman, J. & $\begin{array}{l}\text { Achievement of scale economy gains. } \\
\text { Market power avoidance. } \\
\text { Transaction cost minimization. } \\
\text { Institutional environment and support. }\end{array}$ \\
\hline Chlebika, A., Pietrzak, M. & $\begin{array}{l}\text { Kinship bonds in smaller organizations. } \\
\text { Acquaintance relationships in larger organizations. } \\
\text { Bridging social capital in larger organizations. }\end{array}$ \\
\hline Cook, M.L. & $\begin{array}{l}\text { Continuous, successful tinkering. } \\
\text { Cooperative genius process. } \\
\text { Fundamental solutions to high ownership costs while keeping market } \\
\text { contracting costs low. }\end{array}$ \\
\hline Elliott, M., Elliott, L., Van der Sluis, E. & $\begin{array}{l}\text { Member diversity on farm size. } \\
\text { In the short run: greater member aging, more member asset value, } \\
\text { greater value added at the farm level. }\end{array}$ \\
\hline $\begin{array}{l}\text { Giagnocavo, C., Galdeano-Gomez, E., } \\
\text { Perez-Mesa, J.C. }\end{array}$ & $\begin{array}{l}\text { Capacity to constantly adapt to and address industry crises } \\
\text { and challenges. }\end{array}$ \\
\hline Grashuis, J. & Ability to adapt to dynamic, as opposed to static situations. \\
\hline Iliopoulos, C., Valentinov, V. & $\begin{array}{l}\text { Designing and implementing fundamental (as opposed to symptomatic) } \\
\text { solutions to excessive heterogeneity-induced high ownership costs. }\end{array}$ \\
\hline Tortia, E.C. & $\begin{array}{l}\text { Non-divided ownership of assets, when tragedies of the commons-like } \\
\text { social dilemmas are overcome. }\end{array}$ \\
\hline
\end{tabular}

\section{The Limiting Factors of Cooperative Longevity: A Methodological Reflection}

In view of the diversity and complexity of the determinants of cooperative longevity, we suggest that their investigation, at least at a meta-level, can be usefully informed by the distinction between what we call the first-best and the second-best approach. The former approach would draw inspiration 
from the nonprofit economics literature, which differentiates between the demand-side and supply-side theories of the nonprofit sector $[14,15]$. Whereas the demand-side theories explore the types of societal needs met by nonprofits, the supply-side theories underscore the importance of the behavior of nonprofit entrepreneurs and managers, i.e., of those agents who are responsible for the supply, rather than for the demand, of the nonprofit organizational form. Valentinov and Vacekova [15] argue that the supply-side theories of the nonprofit sector essentially present the theories of its sustainability and implementation problems. This argument seems to have a valid core. If the fundamental purpose of nonprofits is seen in meeting societal needs, then the success of these nonprofits in doing so must indeed be determined by their capacities to address the organizational sustainability and implementation challenges. In principle, this core is quite applicable to the context of the cooperative longevity explored in the present Special issue. In the suggested context, the demand-side theories would be concerned with the ways cooperatives meet member needs, whereas the supply-side theories would explore the challenges of organizational sustainability experienced by cooperatives. Accordingly, whereas the fundamental purpose of cooperatives could be seen as the object of the demand-side explanations, the supply-side explanations would be concerned with the success, longevity, and sustainability of cooperatives.

Unfortunately, this framing of the problem of cooperative longevity, while lucid and straightforward, likely fails to do justice to the diversity and complexity of the determinants of cooperative longevity in the real world. It is for this reason that the exploration of these determinants may need to be guided by the second-best rather than the first-best approach. The difficulty with Valentinov and Vacekova's [15] argument, as the authors themselves acknowledge, is that "the distinction between the demand-side and supply-side determinants is much easier to draw in theory than in practice" ([15], p. 9892). In the case of the Czech rural non-profits explored by the authors, the supply-side and demand-side determinants of these organizations turned out not only to be ambiguously interrelated but even to work at cross-purposes. Consequently, and in contrast to the first-best approach, the second-best approach would no longer seek to uphold the grand distinction between the fundamental organizational purpose and the challenges of organizational sustainability and implementation. Instead, the latter approach would merely encourage an empirical examination of the critical and limiting factors of organizational sustainability. In fact, this is precisely what the contributions to the Special issue deliver; they identify a range of empirically valid and theoretically plausible determinants of how cooperatives manage to retain longevity in the midst of the dramatically dynamic and hostile environment.

The idea of limiting factors is well established in systems literature (cf. [16]) and has been prominently emphasized by John Commons, a classic of American institutionalism [17]. In the cooperative context, this idea has been given a thorough scrutiny by Ernst Grünfeld (1883-1938) in the popular cooperative textbook that he coauthored with Karl Hildebrand in 1929 [18]. Grünfeld [18] provides an account of how cooperatives develop indifference, or lacking sensitivity, to crucial environmental aspects that overtime turn into the key limiting factors of cooperative sustainability. He showed that, while originally pursuing social or ideological goals, cooperatives potentially come to develop indifference to their original ideology and even to the needs of their members. Moreover, acknowledging that cooperatives often arise as a counterweight to the capitalist economy, they used to be marked by an indifference to capital accumulation and profit seeking, thereby becoming increasingly susceptible to the critical factors of limited access to capital and the problems of competitiveness. Thus, to Grünfeld, cooperatives appear as autonomous social systems that are potentially decoupled from both member needs and market requirements, with both types of decoupling eventually posing serious risks to cooperative longevity. The contributions to the present Special issue likewise explore various critical factors of cooperative longevity and thus update and operationalize Grünfeld's basic typology.

An inquiry into the nature of the limiting factors evidently dispenses with the clean distinction between the determinants of the fundamental purpose of cooperatives and the determinants of organizational sustainability. Grünfeld's conjectures on the alienation of cooperatives from members' 
needs make it difficult to uphold this distinction; the same seems to be true of the contributions to the present Special issue. On the one hand, Iliopoulos and Valentinov [12] differentiate between the fundamental and symptomatic solutions to cooperative longevity, insinuating that the former solutions, at a minimum, call for clarity on how the fundamental cooperative purposes are seen by cooperative members. On the other hand, the dramatic structural change, particularly in the agrifood systems of the Western hemisphere, involves a real possibility that the members may not necessarily see the cooperative as a major vehicle for the realization of their economic interests. Numerous cooperative conversions into investor-owned businesses indicate that this possibility ought not to be underestimated. Against this backdrop, it seems a more sound strategy to inquire which of the limiting factors are most significant in relative terms, rather than to assume the existence of fundamental purposes, which are given but imperfectly realized due to the limiting factors pertaining to the sustainability and implementation problems. An alternative strategy, implicit in Michael Cook's contribution to the Special issue [6], is to see cooperative purpose, along with organizational culture and member-patron ownership rights, as a contingent factor that stands ready to revision in the light of the evolving circumstances. A profound implication of this argument is that, even though the nature of cooperative purpose influences the choice of the right tinkering strategy, this purpose cannot be defined independently of organizational culture and member-patron ownership rights. All in all, it is clear that the contributions to the Special issue provide a wealth of evidence for reflecting on which of the diverse limiting factors of cooperative longevity are most limiting and most formative of the evolving cooperative purpose.

\section{Pieces of the Puzzle Missing?}

The research reported in this special issue identifies a number of factors that explain extended cooperative longevity. Yet, there remain more than a few questions to address. A partial list of such questions would include the following:

- Is cooperative longevity a prerequisite of cooperative's success in achieving their members' objectives?

- Is cooperative longevity a reliable indicator of, and proxy for, organizational efficiency?

- Is cooperative longevity more critical than other measures of cooperative health?

- Why, despite Nourse's suggestion [19], their members do not liquidate agricultural cooperatives, after they have corrected for perceived market failures?

- How do Ostrom's core design principles for the efficacy of groups compare with and inform the factors identified in this issue as explanatory of extended cooperative longevity?

- Are ICA's current cooperative principles compatible with the aforementioned factors and the suggestions of recent research?

- What is the nature of the relationship between cooperative longevity and sustainability?

- Is the fractal-like structure of emerging entrepreneurial networks [20] applicable to cooperative development and growth in the 21st century and what would the implications be for cooperative longevity?

Research focusing in these and related questions needs to provide both new conceptual frameworks and empirical answers. The emerging systems thinking approach to cooperative theory and practice seems to be a promising research avenue to tackle the complex issue of cooperative longevity.

Author Contributions: Authors have contributed equally to this Editorial.

Funding: This research received no external funding.

Conflicts of Interest: The authors declare no conflict of interest. 


\section{References}

1. Eversull, E.E. Number of Ag co-ops celebrating 100th anniversaries on the rise. Rural Coop. 2014, 81, 18-23.

2. Bijman, J.; Iliopoulos, C.; Poppe, K.J.; Gijselinckx, C.; Hagedorn, K.; Hanish, M.; van der Sangen, G. Support for Farmers' Co-Operatives; Final Report; European Commission: Brussels, Belgium, 2012.

3. ICA. Global 300 Report: The World's Major Co-Operatives and Mutual Businesses; International Co-Operative Alliance: Geneva, Switzerland, 2011.

4. Bijman, J. Exploring the sustainability of the cooperative model in dairy: The case of The Netherlands. Sustainability 2018, 10, 2498. [CrossRef]

5. Chlebicka, A.; Pietrzak, M. Size of membership and survival patterns of producers' organizations in agriculture-Social aspects based on evidence from Poland. Sustainability 2018, 10, 2293. [CrossRef]

6. Cook, M.L. A life cycle explanation of cooperative longevity. Sustainability 2018, 10, 1586. [CrossRef]

7. Cook, M.L.; Iliopoulos, C. Generic solutions to coordination and organizational costs: Informing cooperative longevity. J. Chain Netw. Sci. 2016, 16, 19-27. [CrossRef]

8. Elliott, M.; Elliott, E.; Van der Sluis, E. A predictive analytics understanding of cooperative membership heterogeneity and sustainability. Sustainability 2018, 10, 2048. [CrossRef]

9. Hansmann, H. The Ownership of Enterprise; Harvard University Press: Cambridge, MA, USA, 1996; ISBN 0-674-64970-2.

10. Giagnocavo, C.; Galdeano-Gomez, E.; Perez-Mesa, J.C. Cooperative longevity and sustainable development in a family farming system. Sustainability 2018, 10, 2198. [CrossRef]

11. Grashuis, J. An exploratory study of cooperative survival: Strategic adaptation to external developments. Sustainability 2018, 10, 652. [CrossRef]

12. Iliopoulos, C.; Valentinov, V. Member heterogeneity in agricultural cooperatives: A systems-theoretic perspective. Sustainability 2018, 10, 1271. [CrossRef]

13. Tortia, E.C. The firm as a common. Non-divided ownership, patrimonial stability and longevity of co-operative enterprises. Sustainability 2018, 10, 1023. [CrossRef]

14. Steinberg, R. Economic theories of nonprofit organization. In The Nonprofit Sector: A Research Handbook, 2nd ed.; Powell, W., Steinberg, R., Eds.; Yale University Press: New Haven, CT, USA; London, UK, 2006; pp. 117-139.

15. Valentinov, V.; Vacekova, G. Sustainability of rural nonprofit organizations: Czech Republic and beyond. Sustainability 2015, 7, 9890-9906. [CrossRef]

16. Meadows, D.H. Thinking in Systems: A Primer; Earthscan: London, UK, 2009.

17. Commons, J.R. Institutional Economics: Its Place in Political Economy; Transaction Publishers: New Brunswick, NJ, USA, 2005.

18. Grünfeld, E.; Hildebrand, K. Genossenschaftswesen: Seine Geschichte, Volkswirtschaftliche Bedeutung und Betriebswirtschaftslehre; Industrieverlag Spaeth \& Linde: Berlin, Germany, 1929.

19. Nourse, E.G. The Place of the Cooperative in Our National Economy; American Institute of Cooperation: Washington, DC, USA, 1945; pp. 33-39.

20. Henderson, T.L.; Boje, D.M. Organizational Development and Change Theory: Managing Fractal Organizing; Routledge: New York, NY, USA; London, UK, 2015; ISBN 978-1-138-80120-2.

(c) 2018 by the authors. Licensee MDPI, Basel, Switzerland. This article is an open access article distributed under the terms and conditions of the Creative Commons Attribution (CC BY) license (http://creativecommons.org/licenses/by/4.0/). 